\title{
ESTRATÉGIA DE INTERNACIONALIZAÇÃO ATRAVÉS DE UPGRADING FUNCIONAL
}

\author{
Eduardo Smaniotto \\ Mestre em Administração pela Unisinos \\ Executivo de vendas do setor calçadista \\ smaniotto@hotmail.com \\ Ely Laureano Paiva \\ Coordenador do Mestrado e Doutorado em Administração da FGV EAESP \\ ely.paiva@fgv.br \\ Luciana Marques Vieira \\ Professora adjunta PPG Administração Unisinos \\ Imvi2003@yahoo.co.uk
}

Recebido em 16/maio/2011 Aprovado em 25/agosto/2012

\section{RESUMO}

Este artigo discute a participação de empresas brasileiras em cadeias globais de valor, tendo como foco do estudo uma empresa do setor calçadista. A maioria das empresas deste setor ainda concentra seus esforços na exportação indireta, participando de maneira reativa nas cadeias globais de valor calçadista. Neste estudo, destaca-se a estratégia adotada por uma empresa brasileira no mercado alemão que busca se internacionalizar com marca própria, desenvolvendo o chamado upgrading funcional. Este direcionamento rompe com a lógica da governança de cadeia exercida pelos varejistas internacionais (buyer-driven). Os métodos utilizados foram o grupo de foco e o estudo de caso da empresa "A". O estudo encontra similaridades com conceitos propostos sobre cadeias globais de valor e analisa a mudança no posicionamento estratégico da empresa. Os resultados contribuem para o entendimento das mudanças estratégicas necessárias para estágios mais avançados de inserção das empresas brasileiras nos mercados externos.

Palavras-Chave: : Internacionalização; estratégia funcional; cadeia de valor; governança; cadeia global.

\section{ABSTRACT}

This article analyzes the Brazilian companies'participation in global value chains, focusing on a footwear company. Most companies of this sector concentrated their efforts through indirect exports, meaning a reactive strategy in the global chain. In this study, we show a different strategy adopted by a Brazilian company in the German market, which includes branding and functional upgrading. This strategy changes the kind of chain governance existent that is led by international retailers (buyer-driven chain). The research methods included a focus group and a case study. The study found similarities with concepts related to the global value chains and analyzed the change in the company's strategic positioning. The results indicate some strategic changes needed for an increasing insertion of Brazilian companies in international markets.

Keywords: Internationalization; functional strategy; value chain; governance; global value chain. 


\section{INTRODUÇÃo}

A internacionalização é um tema recente no ambiente empresarial brasileiro. Segundo Dicken (2003), é necessário distinguir processo de internacionalização, o qual envolve a extensão ou aumento do alcance geográfico de atividades econômicas além das fronteiras domésticas, de globalização, a qual é qualitativamente distinta porque envolve integração funcional de atividades dispersadas internacionalmente. Globalização, segundo Govindarajan e Gupta (2001), refere-se à crescente interdependência econômica entre países (ligada diretamente às empresas), refletida também no crescente fluxo, pelas fronteiras, de mercadorias e serviços, de capital e de conhecimento.

A maioria das empresas calçadistas do sul do Brasil ainda concentra seus esforços na exportação indireta, sendo ele apenas um estágio inicial de internacionalização (JOHANSON; VAHLNE, 1977). Segundo Costa (2004), o destacado desempenho histórico das exportações de calçados do Brasil deve-se a um conjunto de fatores que alavancaram a produção para o exterior: países desenvolvidos em busca de condições mais favoráveis para a produção; base de produção local com capacidade de expansão; mão-de-obra abundante e barata; incentivos fiscais e financeiros; iniciativas locais para atração de compradores; política cambial de manutenção do valor da moeda brasileira.

O setor tem enfrentado crescentes dificuldades devido à elevada concentração existente no modelo tradicional de venda de produção, usualmente via trading companies, caracterizando a estratégia como buyer-driven, apoiada totalmente na decisão do comprador estrangeiro, o que limita a margem de lucro das empresas. Soma-se a este fator a concorrência com a produção chinesa de calçados, que se baseia fortemente na competição por custo. Uma forma de buscar nova fonte de vantagem competitiva é o chamado upgrading industrial, que compreende a busca de nichos econômicos mais rentáveis ou mais sofisticados tecnologicamente.

A questão de pesquisa que aparece a partir deste contexto pode ser assim endereçada: como é o processo de internacionalização dentro de uma proposta de upgrading industrial em um setor que caracteristicamente tem perdido sua competitividade?

Deste modo, analisa-se, o caso de uma empresa calçadista brasileira que busca se internacionalizar com marca própria e assim romper a lógica da cadeia buyerdriven, característica do setor calçadista brasileiro. Focase a prospecção, entrada e investimento no mercado europeu e analisa-se prioritariamente sua entrada no mercado alemão, um dos principais países da comunidade européia.

O artigo apresenta, na sequência, o referencial teórico sobre cadeias globais de valor e estratégias de internacionalização, sugerindo um framework teórico de análise. Na seção 3, apresenta-se o método do estudo. A seção 4 apresenta os principais resultados do estudo de caso com a aplicação do framework desenvolvido e, por fim, a seção 5 discorre sobre as considerações finais do trabalho.

\section{Referencial Teórico}

\subsection{Cadeias Globais de Valor}

No princípio dos anos 80, acadêmicos de escolas de negócios internacionais, como Bruce Kogut (1985) e Michael Porter (1980), desenvolveram modelos teóricos para proporcionar melhor entendimento da situação do comércio internacional e das indústrias da época. Decorre destes estudos iniciais, o estudo de conglomerados industriais, também chamados clusters (PORTER, 1990) e das cadeias globais de commodities (GCC - Global Commodities Chains). Porter (1980) sugere o que optou por chamar de 'Sistema de Valor'. Para Gereffi e(2005, p.167), entretanto, “o estudo das GCC foi baseado em um insight devido à crescente importância de compradores globais como peças centrais na formação de redes de produção e distribuição dispersas internacionalmente”.

Nas primeiras publicações, Gereffi usava o termo GCC, posteriormente adotou GVC por entender que as Global Value Chain (GVC) sugeriam apenas aplicação a situações de produtos commodities. Em diversas publicações (1994, 1999, 2001 e 2005), o citado autor afirma que o conceito de GVC difere de clusters 
basicamente na unidade de análise. Este último foca a firma individual e a GVC enfoca a cadeia produtiva e seus elos (fornecedores e distribuidores) globais.

De forma mais ampla, para Gereffi e Korzeniewicz (1994), cadeia global de valor se refere a todas as atividades envolvidas no desenvolvimento, produção e marketing de um produto. Schmitz (2004) argumenta que se trata de toda atividade produtiva organizada por meio de redes de empresas legalmente independentes, com uso de uma variedade de relações interorganizacionais.

Kogut (1985) elaborou o papel principal da cadeia de valor no desenho de estratégias internacionais de negócios, as quais são posicionadas entre as vantagens comparativas de países e as vantagens competitivas de empresas. A lógica da vantagem comparativa auxilia na determinação de onde a cadeia de valor deve ser dividida além-fronteiras, ou seja, quais atividades devem ser desenvolvidas e em que país. A vantagem competitiva influencia a decisão em quais atividades e tecnologias a empresa deve concentrar seus recursos ao longo da cadeia de valor.

Conforme Gereffi (2001a), o modelo GVC é útil para a análise e a avaliação de setores globais de indústria. Assim como na perspectiva tradicional de cadeias de valor, a cadeia global de valor é baseada no fluxo de mercadorias envolvidas na produção e na distribuição de produtos. Segundo Porter (1990), ela difere em pelo menos quatro pontos de sistemas de negócio ou cadeia de valor: incorpora explicitamente a dimensão internacional na análise; foca no poder exercido pela empresa líder em diferentes segmentos da cadeia de valor e ilustra como o poder muda através do tempo; visualiza a coordenação de toda a cadeia como um fator chave de vantagem competitiva, que requer o uso de redes como ativo estratégico e reconhece no aprendizado organizacional, o mecanismo crítico pelo qual empresas tentam melhorar ou consolidar sua posição na cadeia.

Para Schmitz (2004), governança da cadeia global de valor tem relação com o exercício de coordenação e de controle da cadeia de valor. Em qualquer ponto da cadeia, as atividades desenvolvidas são definidas por um conjunto de parâmetros. Os três parâmetros-chave são: o que deve ser produzido - desenho do produto e especificações; como deve ser produzido - envolve a definição dos processos de produção, os quais incluem elementos como a tecnologia a ser utilizada, os sistemas de qualidade, os padrões de trabalho e ambientais; quanto e quando deve ser produzido - programação de produção e logística (SCHMITZ, 2004).

Ainda segundo o mesmo autor, o conceito de governança é central no estudo de cadeias globais de valor. Este termo é usado para expressar como algumas empresas na cadeia estabelecem ou impõem os parâmetros pelos quais as outras devem operar. Uma cadeia sem governança seria apenas uma corrente de relações de mercado. Segundo Bazan e Navas-Alemán (2004), quando uma cadeia não possui claramente tipos de governança buyer-driven ou producer-driven, ela é caracterizada por relações baseadas no mercado.

Buyer driven é característica do setor calçadista global e refere-se àquelas nas quais grandes varejistas, intermediários e fabricantes com marca própria exercem papel chave em estabelecer redes de produção descentralizadas em uma série de países exportadores, tipicamente localizados em países emergentes. Como exemplos podem ser citados: Wal-Mart, Sears, JCPenney, Nike, Reebok, Liz Claiborne (GEREFFI, 2001). Além disso, em setores automotivos, a governança é do tipo producer-driven, ou seja, o fabricante possui poder sobre a cadeia.

Para Schmitz, "governança refere-se às relações interfirmas e aos mecanismos institucionais, através dos quais, a coordenação não explícita das atividades é exercida" (2004, p.97). Para Gereffi (1999), governança da cadeia de valor é a coordenação de atividades diferentes e dispersas envolvidas na cadeia. Bazan e Navas-Alemán (2004) afirmam que fica claro que as implicações da governança em uma cadeia de valor vão muito além de meramente organizar as atividades, a governança está intimamente ligada ao upgrading e à distribuição de ganhos através da cadeia.

Com base nos conceitos anteriormente descritos, pode-se afirmar que a governança global refere-se à liderança e ao controle de todos os processos de uma 
cadeia global de valor, incluindo a decisão (nem sempre explícita) da distribuição dos ganhos e do desenvolvimento através dos diversos componentes da mesma cadeia. Esta governança pode ser considerada producer-driven ou buyer-driven.

Mais recentemente, Gereffi, Humphrey e Sturgeon (2005) propuseram uma nova tipologia baseada em três variáveis independentes: complexidade das informações e conhecimento requerido; extensão na qual estas informações e conhecimentos podem ser codificados; e as competências dos atuais e potenciais fornecedores. Estes cinco tipos de governança são:

1. Mercado: ligações de mercado existentes em todo o tempo e não transitórias;

2. Cadeia de valor modular: produtos específicos para cada cliente;

3. Cadeia de valor relacional: ligações complexas entre compradores e vendedores resultando em uma dependência mútua;

4. Cadeia de valor prisioneira: pequenos fornecedores dependentes de grades compradores;

5. Hierarquia: integração vertical.

Emily Gereffi (2004) estudou o processo de construção de marcas calçadistas no Vale do Sinos e o upgrade destas empresas. A autora apresentou a cadeia global de valor para o setor calçadista brasileiro da seguinte forma:

Design - a primeira atividade da cadeia trata da concepção do produto. Segundo Gereffi (2004), inicialmente os estilistas criam um conceito e definem pontos como formato de fôrma e salto e materiais a serem usados. Seguem-se processos de prototipagem e aprovação parcial antes da aprovação final do produto. A qualidade do design é um fator determinante na diferenciação do produto. A autora conclui que esta atividade adiciona maior valor ao processo do que a produção, que pouco contribui para esta diferenciação. Portanto, design inovador é particularmente importante na indústria calçadista, em que o gosto dos consumidores seguidores de moda é caprichoso e volátil.

Produção - a segunda atividade da cadeia global de valor calçadista compreende desde a fabricação de componentes e dos maquinários utilizados na fabricação de calçados até a própria fabricação do calçado. Esta atividade, por ser altamente baseada em custos, não permite grande diferenciação dentre os diversos produtores mundiais (GEREFFI, 2004).

Logística - envolve não apenas o transporte do produto final, mas também o formato de comunicação e o relacionamento entre produtor, distribuidores e varejistas (GEREFFI, 2004). Este é um dos pontos cruciais na discussão da governança da cadeia, pois é justamente nesta atividade que encontram-se as várias modalidades de internacionalização, como exportação direta, alianças estratégicas, joint ventures e investimentos diretos.

Marketing - engloba diversos processos da indústria calçadista, incluindo desenvolvimento de marca e publicidade. Esta atividade tem conexão direta com o design. A criação de marca é um dos pontos mais complexos desta atividade (GEREFFI, 2004).

Varejo - a atividade final da cadeia global de valor é o varejo, tanto local quanto internacional. É possível existir diferença substancial de estrutura de varejo em diferentes países (GEREFFI, 2004).

É usual o entendimento parcial do conceito de cadeia de valor (EVANS; WURSTER, 2000). Encontrase ocasionalmente a falsa idéia que supply chain e cadeia de valor sejam o mesmo. Evans e Wurster (2000) argumentam que supply chains conectam vendedores e compradores, usando a mesma lógica de informação das cadeias de valor entre as empresas, entretanto sem o mesmo nível de comprometimento de ativos ou de investimentos. Outra distinção entre os dois conceitos é que supply chain deve ser conceitualizada como o transporte físico de mercadorias, tipicamente associado com logística, fabricação, entrega, etc. Cadeia de valor, por distinção, incorpora operações de supply chain, bem como atividades de conhecimento, como P\&D e administração. O termo cadeia de valor é, portanto, mais 
amplo e mais inclusivo (LAWTON; MICHAELS, 2001).

Segundo Paiva e Hexsel (2004), o processo de internacionalização é um desafio para as empresas brasileiras quando se analisa a complexidade deste processo através das atividades da cadeia de valor e das possíveis decisões tomadas durante ele. A estratégia de internacionalização influencia diretamente a decisão da proposta de valor adotada pela empresa, ou seja, de que forma os critérios competitivos são dispostos ao longo da sua cadeia de valor.

A cadeia de valor mencionada pelos autores citados e referida no presente trabalho é aquela que trata da cadeia de valor própria da empresa, ou seja, dos processos internos. As atividades de marketing e de vendas não são consideradas nesta adaptação do trabalho original de De Toni e Forza (1992), por não estarem sob responsabilidade da gestão de operações (Figura 1).

Figura 1 - Cadeia de Valor de Operações

\begin{tabular}{|c|c|c|c|c|}
\hline \multicolumn{5}{|c|}{ Critérios competitivos } \\
\hline & 0 & & & \\
\hline$P \& D$ & $\begin{array}{c}\text { de } \\
\text { Fornecimento }\end{array}$ & Produção & $\begin{array}{c}\text { de } \\
\text { Distribuição }\end{array}$ & Serviço \\
\hline
\end{tabular}

Fonte: adaptado de Porter (1986) e De Toni e Forza (1992)

Conforme Paiva, Carvalho Jr. e Fensterseifer (2004), as atividades da cadeia de valor da empresa devem estar alinhadas de forma que a estratégia de operações adotada ofereça valor ao cliente, dentro daquilo que ele busca. Para estes autores, a contínua adequação das atividades da empresa é necessária, pela avaliação sistemática do formato existente. Eliminação deatividades desnecessárias e readequação entre atividades existentes e prioridades competitivas são decisões possíveis que permitem, por exemplo, maior aproximação entre cliente e operações e, consequentemente, a competência de a empresa reagir mais rápido às mudanças nos hábitos e desejos dos clientes (PAIVA, CARVALHO JR.; FENSTERSEIFER,
2004).

Uma das possíveis consequências decorrentes do processo de análise da cadeia de valor da empresa é a necessidade de integração vertical de processos, estendendo a abrangência da atuação a uma cadeia de valor maior.

\subsection{Os Processos de Upgrading e Downgrading das Cadeias Globais de Valor}

Segundo Gereffi (1999), upgrading industrial é o processo de melhorar a habilidade de uma empresa ou de uma economia de se mover para nichos econômicos mais rentáveis e/ou sofisticados tecnologicamente. Segundo o autor, o processo de upgrading industrial ocorre em diferentes níveis de análise (GEREFFI, 1999, p.52):

1) Entre fábricas - envolve mudar de itens baratos para caros, de produtos simples para complexos e de pedidos pequenos para grandes;

2) Entre redes empresariais - envolve mudar de um sistema de produção em massa de produtos padronizados para um sistema de produção flexível de produtos diferenciados;

3) Entre economia local ou nacional - envolve mudar de simples processos de montagem de componentes importados, para sistemas mais integrados, utilizando-se processos de fornecimento locais;

4) Entre regiões - envolve alteração de fluxo de comércio inter-regional, bilateral e assimétrico para uma divisão mais sofisticada de trabalho, dispersando todas as atividades da cadeia de valor, mantendo o controle unificado.

Para Bazan e Navas-Alemán (2004), upgrading pode ter variação de produto (movendo-se para linhas mais sofisticadas de produto), de processo (sendo mais eficiente) e funcional (adquirindo novas funções na cadeia, que agregam mais valor, como branding, marketing e desenvolvimento de produto). Inclui-se 
como upgrading funcional o processo de verticalização (integração) de operações, pois neste caso há abrangência de mais atividades componentes da cadeia por parte da empresa.

Downgrading industrial é o processo inverso ao anteriormente descrito. Rabellotti (2004) apresenta um exemplo de downgrading na região de Brenta na Itália.

Para serem parte da cadeia, os fabricantes de calçados de Brenta aceitaram um downgrading funcional, abandonando desenvolvimento de produto e vendas, que são competências-chave dos líderes da cadeia, e focando em produção somente. Esta história chama a atenção à pelo menos dois aspectos, que não somente upgrading, mas também downgrading pode ocorrer entre as cadeias globais de valor e em produtores líderes de países desenvolvidos (RABELLOTTI, 2004, p.167).

Pietrobelli e Rabellotti (2004) conceituam upgrading como o processo de inovação para aumentar o valor agregado. Na sua proposta, inovação é a evolução em produtos e processos que são novos à empresa e que lhe permitem permanecer apta a competir em um mercado internacional dinâmico. "Isto envolve uma mudança para atividades, produtos e setores que apresentem maior valor agregado e maiores barreiras de entrada ao mercado" (PIETROBELLI; RABELLOTTI, 2004, p.6).

O principal motivo de uma empresa buscar o upgrading é tornar-se mais competitiva e sólida e assim garantir sua existência. Pietrobelli e Rabellotti (2004) afirmam que o upgrading funcional é fundamental:

“Upgrading funcional também provavelmente reduz fraquezas e vulnerabilidades em uma especialização de produto [...] possibilita a aquisição de vantagens competitivas mais resistentes e sólidas” (PIETROBELLI; RABELLOTTI, 2004, p.7).

Sempre que uma empresa atua em uma cadeia global de valor como um player que busca upgrades ao longo de sua participação, deve estruturar sua atuação de forma a ser competitiva.

\subsection{Estratégias de INTERNACionalizaÇão}

Existem diversas abordagens na literatura sobre internacionalização e possivelmente, por isso, o conceito de internacionalização não é consensual entre os diversos estudiosos. A maioria dos pesquisadores tem descrito internacionalização como o movimento externo nas operações internacionais de uma empresa (TURNBULL, 1987). Outros interpretaram internacionalização como o processo seqüencial e ordenado de crescente envolvimento internacional e as mudanças associadas na estrutura da organização (CAVUSGIL 1980, JOHANSON;VAHLNE, 1977). Segundo Melin (1992), internacionalização pode ser percebida como parte do processo estratégico de negócios existente de muitas empresas. Para Andersen (1997), as principais diferenças entre internacionalização e outros tipos de processos estratégicos reside em duas dimensões. A primeira é a questão das fronteiras, em que a empresa transfere produtos, serviços ou recursos através de fronteiras internacionais. Desta dimensão, origina-se a necessidade da seleção dos mercados ou países em que estas transações devem ocorrer. A segunda é a tomada de decisão sobre onde executar as transações e a seleção da forma de execução, denominada 'modo de entrada' ou estratégia de entrada. Root (1987) define estratégia de entrada como arranjos institucionais que possibilitam a entrada de produtos, tecnologia, habilidades humanas, gerenciamento ou outros recursos em um país estrangeiro. Segundo Andersen (1997), estas duas dimensões seleção internacional de mercados e escolha da estratégia de entrada - representam decisões estratégicas-chave no que se refere à internacionalização de empresas. Soma-se a elas a complexidade adicional no composto estratégico, devido a problemas de coordenação e controle, gerados pelas ações de agentes estrangeiros e por políticas de governos estrangeiros (LU; BEAMISH, 2001).

Com base nestas dimensões e considerando o embasamento teórico apresentado por Andersen (1997), adota-se, a definição de internacionalização como o processo dinâmico de adaptação de modalidades de transação para mercados internacionais. Nesta definição, fica claramente expresso o caráter dinâmico do processo de internacionalização. Embora contenha a palavra 'processo', esta definição não indica que a internacionalização deva ser obrigatoriamente composta 
por características evolutivas, através de etapas seqüenciais rígidas e impositivas. Segundo Arruda, Brasil e Goulart (1996), pode-se, em geral, descrever o seguinte padrão: empresa não-exportadora; exportadora via agente; exportadora via escritório de vendas; marketing e assistência pós-venda no exterior; implantação de subsidiária de produção no exterior.

Rocha (2002) afirma que as atividades de internacionalização de uma organização podem ser classificadas em dois grupos, de acordo com o mercado no qual a empresa deseja competir ou melhorar sua competitividade: internacionalização para fora - outward - do mercado interno para o externo: exportação (predominantemente no elenco de atividades internacionais das empresas brasileiras), abertura de escritórios, instalação de fábricas, joint ventures e alianças estratégicas; internacionalização para dentro inward - do mercado externo para o interno: alianças, franquias e transferência de tecnologias entre empresas multinacionais e empresas brasileiras.

Pan e Tse (2000) desenvolveram o modelo hierárquico de estratégias de entrada. Os autores argumentam que as estratégias de entrada podem ser examinadas a partir de uma perspectiva hierárquica - os gerentes tomadores de decisão primeiramente classificam as várias opções de entrada em níveis multi-hierárquicos e definem um conjunto de critérios de avaliação para cada nível. O primeiro nível hierárquico fica entre estratégias com envolvimento de ativos físicos ou não; o nível seguinte de decisão diz respeito a qual estratégia de entrada a ser adotada. Para os autores, a exportação e acordos contratuais são estratégias de entrada sem envolvimento de ativos físicos. O investimento direto e joint-ventures são estratégias com envolvimento de ativos físicos.

O investimento em instalações no exterior pode ser motivado pela percepção da empresa da amplitude do mercado estrangeiro. Assim vantagens podem ser obtidas, tais como: redução de custos de mão-de-obra ou matériasprimas; incentivos fiscais e economia de frete; melhora da imagem da empresa no mercado estrangeiro devido ao número de empregos que vai gerar; aprofundamento do relacionamento com governo, consumidores, fornecedores locais e distribuidores, permitindo melhor adaptação de seus produtos ao mercado local. O pleno controle sobre o investimento permite o desenvolvimento de políticas de produção e marketing que atendam aos objetivos globais da empresa em longo prazo (KOTLER, 1998). Outros benefícios são apresentados por Cateora (1999), que ressalta a motivação derivada da eliminação de taxas de importação para a comercialização de produtos e serviços nos mercados onde o investimento externo será realizado, bem como em outros países que possuam acordos tarifários melhores do que com o país sede da organização.

A principal desvantagem é a exposição da empresa a riscos, como bloqueio ou desvalorização de moeda, mercados declinantes ou expropriação (KOTLER, 1998). Trata-se da estratégia que exige o maior envolvimento da empresa com o mercado estrangeiro, envolvendo maiores riscos. Fatehi (1996) afirma que esta é a estratégia mais complexa de internacionalização, visto que envolve a capacidade de gestão de recursos físicos para a produção de bens em mercados estrangeiros.

Embora muitos esforços sejam depositados no sentido de aumentar a participação do Brasil no mercado mundial, esta ainda é muito pequena comparativamente a outros países em desenvolvimento (ARRUDA, BRASIL; GOULART, 1996).

Conforme Buckley (1996), pode-se considerar três estágios na internacionalização das empresas brasileiras em relação aos mercados de atuação: internacionalização para o mercado doméstico - a finalidade deste estágio é acentuar a capacidade competitiva da empresa no mercado doméstico, através da aquisição de tecnologias e habilidades no exterior, inclusive através da aquisição de empresas estrangeiras; internacionalização regional - expansão através do MERCOSUL (Mercado Comum do Sul) e do mercado sul-americano, e; internacionalização completa - entrada nos mercados de países desenvolvidos.

A cadeia calçadista exportadora do Rio Grande do Sul está predominantemente organizada numa lógica buyerdriven, ou seja, as características e preços dos calçados são determinados pelos varejistas estrangeiros. Nesta lógica, as empresas exportam via trading companies e focam nas atividades de manufatura. O estudo de caso em questão descreve como uma empresa tenta romper 
com esta estrutura ao implementar uma estratégia de internacionalização diferenciada para entrada em um mercado específico, o alemão, utilizando seu design e marca.

O framework teórico proposto se alicerça inicialmente na cadeia de valor de operações de uma empresa composta pelos processos internos, como P\&D, logística de fornecimento, produção, logística de distribuição e serviço. Estes são entendidos como a base de recursos e capacidades da empresa para a formulação de uma estratégia de internacionalização sustentada, que possa gerar vantagem competitiva.

A partir de seus recursos e suas capacidades, seus processos são alinhados com a proposta de valor mais adequada para competição internacional, a empresa insere-se em uma cadeia global de valor. Na figura 2 a empresa está representada pelo retângulo de linha mais espessa, inserida dentro da cadeia global de valor (círculo externo).

Como decisão estratégica, também se insere a decisão de integração vertical, tanto para frente, quanto para trás (HARRIGAN, 1984; STUCKEY;WHITE, 1993). Nesta decisão, surgem pontos importantes que determinam quanto do valor adicionado através da cadeia de valor pode ser mantido pela empresa. Vê-se esta possibilidade na figura 2 através da seta, representando o sentido da ação da empresa, partindo de sua estrutura interna, para a cadeia global de valor.
Como apresentado na Figura 2, esta cadeia tende a ter sua governança nas lógicas buyer-driven. (GEREFFI, 2001a) ou ser regida pelo que Bazan e Navas-Alemán (2004) e Gereffi (2005) sugerem como relações baseadas no mercado.

As possíveis governanças estão também representadas na figura acima através das setas. Quando governança producer-driven, a seta demonstra o sentido do movimento organizacional, partindo do interior da organização, para a cadeia global de valor. Já na governança buyer-driven, a seta indica o controle do comprador sobre a distribuição dos ganhos através da cadeia. Na seta que representa as relações de mercado, observa-se o equilíbrio dentre os players da cadeia global, havendo movimento bi-direcional entre a cadeia global e a cadeia de valor de operações de uma empresa.

\section{MÉTodo}

Neste estudo, analisa-se o caso da empresa “A”, parte de um grupo empresarial de grande porte do Rio Grande do Sul e sua estratégia de internacionalização no mercado alemão. Neste trabalho, o método de pesquisa empregado foi o estudo de caso descritivo. Adotou-se a técnica chamada de observação participante (ROESCH, 1999, p.248-249), na qual “o pesquisador adquire entendimento das atividades do grupo ao delas participar”.

Yin (2001) considera o estudo de caso como o mais indicado para responder questões de pesquisa do tipo “como” e "por quê", as quais têm caráter explanatório. Neste caso, a raridade de exemplos similares também justifica a escolha metodológica.

Pesquisadores que adotam o estudo de caso buscam o que é comum e o que é particular sobre um caso, o resultado final normalmente apresenta algo único (STOUFER, 1941). Neste ‘algo único’ se encontra a grande limitação crítica desta metodologia. A impossibilidade de extrapolação dos resultados torna o estudo de caso uma análise depurada 
e aprofundada de uma situação específica. Entretanto, mesmo sendo único, o estudo de caso é uma entidade complexa operando dentre vários contextos, incluindo o físico, o econômico, o ético e o estético. O caso é singular, mas tem subseções, grupos, ocasiões, concatenação de domínios - alguns tão complexos que no máximo podem ser amostrados (STAKE, 1994).

Os dados para este estudo foram coletados seguindo uma multiplicidade de fatores:

Pesquisa em dados secundários - realizada em livros, outras publicações, e documentos da empresa

Grupo focal - uma das propostas deste trabalho foi o desenvolvimento de um grupo focal, conduzido por um facilitador externo, com os seguintes objetivos: criticar temas básicos levantados na revisão de literatura; identificar e estruturar novas questões relevantes a serem aprofundadas na pesquisa; suscitar ainda novas visões para possíveis pesquisas futuras.

O grupo focal foi composto por representantes da Abicalçados (Associação Brasileira de Calçados) e da Assintecal (Associação Brasileira de Empresas de Componentes para Couro, Calçados e Artefatos), por um fabricante de calçados, exportador no modelo tradicional (venda de produto sem marca, chamada no setor de venda de produção) e por dois pesquisadores.

Os resultados do grupo focal foram gravados em fitas cassetes e, posteriormente, transcritos para possibilitar melhor análise dos resultados.

Estudo de caso - dados primários - os dados foram coletados pela observação participante e por entrevistas.

As entrevistas na empresa em estudo foram realizadas com as seguintes pessoas: gerente de exportação; gerente de produto; vendedora no mercado alemão e gerente da agência de relações públicas para o calçado brasileiro na Alemanha (programa Brazilian Footwear da Abicalçados).

As entrevistas foram realizadas pessoalmente com todos os entrevistados e as respostas anotadas pelo pesquisador. As entrevistas com a vendedora responsável pelo mercado alemão e com a gerente da agência de relações públicas foram realizadas em inglês e posteriormente traduzidas.
Após a coleta dos dados, foi desenvolvida a análise qualitativa do conteúdo. Segundo Flick (2004), a análise de conteúdo é um dos procedimentos clássicos para analisar o material textual, não importando qual a origem deste material. Para o autor, um dos aspectos essenciais é o emprego de categorias obtidas de modelos teóricos atividade desenvolvida neste estudo. O objetivo principal desta técnica é reduzir o material. Tanto os textos do grupo focal, quanto das entrevistas foram parafraseados e resumidos. Sempre que possível, afirmações similares foram combinadas, expressando uma idéia única. Após a análise de conteúdo, o estudo de caso foi estruturado na mesma seqüência do referencial teórico, de forma a manter a estrutura apresentada no framework teórico proposto.

Além da triangulação realizada pelo cruzamento dos dados provenientes das entrevistas, do grupo focal e dos documentos da empresa, o estudo de caso foi avaliado pelo gestor superintendente da empresa estudada e por um consultor da Abicalçados, visando a validação dos resultados obtidos.

\section{Apresentação e Discussão do Caso}

\subsection{Resultados do Grupo de Foco}

No Quadro 1 são apresentadas as diferenças e as características das estratégias buyer driven e producer driven. Inicialmente, é destacada a governança da cadeia, pelo comprador na estratégia buyer driven e pelo produtor na estratégia producer driven. A análise da integração com o fornecedor evidencia uma grande diferença entre as estratégias: na buyer driven, as relações tendem a ser de curto prazo; na estratégia producer driven, os relacionamentos tendem a ser de longo prazo, contando inclusive com a colaboração entre concorrentes. Um exemplo disto é a indústria automobilística, na qual se observa a cooperação entre concorrentes para o uso de plataformas e motores, visando à redução de custos. Na indústria calçadista, há exemplos similares, em que duas ou mais empresas se associam para a constituição de uma nova empresa fornecedora de matéria-prima ou prestadora de serviços. Outra grande diferença entre as estratégias está no desenvolvimento de produto: na buyer driven, o cliente detém a decisão sobre o produto, determinando padrões visuais e até mesmo técnicos; na estratégia producer driven, o produtor tem gestão plena 
sobre o desenvolvimento do produto, adequando suas competências internas às necessidades do mercado em que atua.

Conforme os participantes do grupo de foco, a estratégia de manufatura empregada pelas empresas do setor de calçados também varia substancialmente. Aquelas que se valem da estratégia buyer driven baseiam sua manufatura em custos e na entrega confiável, as outras (producer driven) baseiam sua estratégia de manufatura em flexibilidade de volume e design. Quando observados pontos como vendas e distribuição, orientação de mercado e perfil de clientes, emergem outras diferenças importantes: as empresas de estratégia buyer driven dependem de terceiros para a comercialização e buscam grandes varejistas como clientes globais, comumente nos EUA e na Europa; as outras producer driven desenvolvem suas vendas em feiras setoriais, valendo-se de equipes próprias de vendas ou de vendedores locais. Atuam também em mercados locais e almejam pequenos e médios varejistas. As diferenças também surgem quando o assunto é qualidade: as buyer driven buscam a conformidade como 'defeito zero'; as producer driven vislumbram as características de produto e a conformidade, mas sem a busca do 'defeito zero'. O maior alcance da estratégia producer driven fica evidente quando a integração vertical é analisada, pois nesta estratégia a integração vertical é crescente, dada a maior proximidade direta com o varejo. Quando os preços praticados são comparados, ficam claras as características de governança da cadeia: na buyer driven os preços ficavam entre 10 e 15 dólares; na producer driven ficam entre 15

Quadro 1: Comparação entre Estratégias Buyer Driven e Producer Driven setor calçadista do Vale dos Sinos

\begin{tabular}{|l|l|l|}
\hline Características & Buyer driven & \multicolumn{1}{|c|}{ Producer driven } \\
\hline $\begin{array}{l}\text { Governança da } \\
\text { cadeia }\end{array}$ & Comprador & Produtor \\
\hline $\begin{array}{l}\text { Integração } \\
\text { fornecedor }\end{array}$ & Curto Prazo & $\begin{array}{l}\text { Longo Prazo } \\
\text { Cooperação mesmo entre } \\
\text { concorrentes }\end{array}$ \\
\hline $\begin{array}{l}\text { Desenvolvimento } \\
\text { de Produto }\end{array}$ & $\begin{array}{l}\text { Dirigida pelo } \\
\text { cliente }\end{array}$ & Próprio \\
\hline $\begin{array}{l}\text { Estratégia de } \\
\text { Manufatura }\end{array}$ & $\begin{array}{l}\text { Eusto } \\
\text { Contregánel }\end{array}$ & $\begin{array}{l}\text { Flexibilidade volume } \\
\text { Design }\end{array}$ \\
\hline $\begin{array}{l}\text { Vendas e } \\
\text { Distribuição }\end{array}$ & $\begin{array}{l}\text { Tradings, } \\
\text { Intermediários }\end{array}$ & $\begin{array}{l}\text { Feiras setoriais } \\
\text { Equipe própria de vendas e } \\
\text { centros de distribuição } \\
\text { vendedores locais }\end{array}$ \\
\hline $\begin{array}{l}\text { Orientação de } \\
\text { mercado }\end{array}$ & $\begin{array}{l}\text { Clientes } \\
\text { Globais } \\
\text { EUA e Reino }\end{array}$ & $\begin{array}{l}\text { Europa, América Latina e } \\
\text { mercado local }\end{array}$ \\
\hline Perfil Clientes & $\begin{array}{l}\text { Grandes } \\
\text { Varejistas }\end{array}$ & Pequenos e médios varejistas \\
\hline $\begin{array}{l}\text { Abordagem } \\
\text { qualidade }\end{array}$ & $\begin{array}{l}\text { Conformidade } \\
\text { (Defeito zero) }\end{array}$ & $\begin{array}{l}\text { Características do produto e } \\
\text { conformidade }\end{array}$ \\
\hline $\begin{array}{l}\text { Integração } \\
\text { vertical }\end{array}$ & $\begin{array}{l}\text { Baixa } \\
\text { integração } \\
\text { vertical }\end{array}$ & $\begin{array}{l}\text { Crescente (fornecimento ao } \\
\text { varejo) }\end{array}$ \\
\hline $\begin{array}{l}\text { Faixa de Preço } \\
\text { (USD) }\end{array}$ & $\begin{array}{l}10 / 15 \\
15 / 29\end{array}$ \\
\hline
\end{tabular}

e 29 dólares - aqui se observa também a diferença na distribuição dos ganhos ao longo da cadeia.

\subsection{A EMPRESA "A"}

O grupo do qual empresa “A” faz parte, dedica-se à fabricação de calçados femininos e esportivos de alta qualidade, ocupando posição de liderança no mercado nacional e destacando-se como o principal exportador brasileiro do setor em produtos de maior valor agregado.

O grupo possui unidades fabris instaladas no Rio Grande do Sul, no Ceará e na Bahia. Além das indústrias, o grupo possui a maior rede varejista de calçados do Brasil com mais de 120 lojas nas regiões Sul, Sudeste e Nordeste do país. Somam-se a isto fazendas no Mato Grosso do Sul, onde há investimentos em agricultura e agropecuária.

Sua capacidade instalada para é de 50 mil pares diários de calçados de maior valor agregado.

As exportações respondem por aproximadamente $74 \%$ do faturamento na operação fabril. As exportações tiveram início no final da década de 60, quando compradores americanos optaram por investir no Vale dos Sinos e alocaram grandes volumes de produção, deslocados de fabricantes europeus, italianos e espanhóis em sua maioria. Por praticamente vinte e sete anos, a operação de fabricação dedicou-se em produção quase exclusivamente para uma grande empresa importadora, distribuidora e varejista de calçados dos EUA.

Com a entrada dos países asiáticos no mercado calçadista global, especificamente a China, na primeira metade da década de 90, a indústria brasileira de calçados sofreu forte impacto em suas exportações, expondo toda a fragilidade de um setor que competia com estratégia de liderança por custo. Não havendo nenhum fator de 
diferenciação, os compradores mundiais iniciaram um movimento de deslocamento de produção para os países asiáticos, que dispunham de melhores condições de preço frente aos fabricantes brasileiros.

A empresa decidiu em 1997 iniciar o desenvolvimento de novas alternativas de negócios, buscando o que Bazan e Navas-Alemán (2004) chamam de upgrading de suas operações, através da criação da Unidade de Negócios “A”, independente tanto comercialmente, quanto industrialmente do grupo.

A unidade de negócios “A” visava inicialmente atender ao mercado doméstico e diversificar o portfolio de negócios de grupo, até então baseado somente em exportações.

Desde o início das exportações com marca própria, em 1999, a “A” apresenta crescimento acentuado em diversos mercados. Ao final de 2002, os calçados eram exportados para 37 países, passando para 44 países, em 2003, e para 52, ao final de 2004.

Em 2005, a exportação correspondia a, aproximadamente, $59 \%$ do volume produzido pela marca e a cerca de $45 \%$ do faturamento bruto (preço médio mais baixo é explicado pela não incidência de impostos como ICMS e PIS/COFINS na exportação, além de custos menores com comissões e outros compostos do preço de venda).

Ao se comparar a evolução das exportações brasileiras de calçado com as exportações da marca "A”, percebese o crescimento da marca. Houve decréscimo de 19\% no ano de 2002 em relação a 2001, resultado decorrente do reposicionamento da marca em termos de imagem e segmento de preços, porém o crescimento foi retomado a partir de 2003, com um resultado 151\% superior ao ano anterior. Em 2004, manteve-se o crescimento:, no período analisado, acumulou 343\% de crescimento, contra 55\% do total das exportações brasileiras, conforme Tabela 1 a seguir.

Tabela 1: Comparativo Evolução Exportações “A” x Brasil

\begin{tabular}{|cc|c|c|c|c|}
\cline { 2 - 6 } \multicolumn{1}{c|}{} & 2001 & 2002 & 2003 & 2004 & $\begin{array}{c}\text { Acumulado } \\
2000-2004\end{array}$ \\
\hline \begin{tabular}{cccc} 
Crescimento “A” \\
\hline $\begin{array}{c}\text { Crescimento } \\
\text { Brasil }\end{array}$
\end{tabular} & $7,9 \%$ & $-19 \%$ & $151 \%$ & $49 \%$ & $343 \%$ \\
\hline
\end{tabular}

Fonte: ABICALÇADOS (2005) e “A” (2005)
Este desempenho apresenta tendência de queda, justificada basicamente por dois motivos: a valorização do Real à época (que gerou aumento de preços nos mercados internacionais e foi um limitador para alguns países com menor poder de compra) e a concentração de esforços no continente europeu, com o objetivo de efetivamente construir uma marca bem posicionada neste mercado. Para o gerente responsável pela unidade européia, marcas são consideradas bem posicionadas apenas quando alcançam boa exposição nas principais capitais de moda, como Milão, Paris, Madrid, Frankfurt e Londres. Dada esta 'necessidade de concentração de esforços, todos os investimentos foram direcionados para a Europa, fazendo com que outros mercados, como o Asiático e o da Oceania, recebam menor atenção, com a conseqüente perda de vendas nestes mercados.

Embora esta situação possa ser questionada, os gerentes entrevistados a entendem como passo necessário para a consolidação da internacionalização, pois a Europa funciona como ‘espelho’ para os países consumidores de moda.

A empresa planeja comercializar 56\% de seu volume de produção fora do Brasil até 2009,aumentar continuamente suas vendas internacionais, do qual um terço seriam destinadas para no continente Europeu. Com a mesma participação, tem-se a América do Norte (32\%), em razão do potencial concentrado nos Estados Unidos, Canadá e México. Nesta perspectiva, a Ásia ocuparia a terceira posição com 13\% do total, a América Latina teria 11\% (Central e do Sul, excluindo-se o México), os 12\% restantes estariam distribuídos entre Oceania, Oriente Médio e África.

\subsection{ESTRATÉGIAS DE INTERNACIONALIZAÇÃo}

Conforme mencionado, as exportações da marca “A” tiveram início incipiente em 1999. Embora o grupo já possuísse grande parte de sua estrutura voltada à exportação, esta se caracterizava por ser do modelo tradicional, aqui denominado venda de produção (COSTA, 2004).

Tendo nascido como marca de mercado doméstico, a exportação da marca "A" se iniciou nos últimos anos. 
Através do contato com importadores argentinos em uma feira brasileira, foi desenvolvido o primeiro processo de exportação do grupo com produto próprio e marca própria. Esta primeira exportação ocorreu de forma direta, sem a utilização de intermediários, o que também representava uma novidade para o grupo, acostumado com a negociação via trading companies. Deste então, as atividades internacionais da marca vêm sofrendo um upgrading estratégico, pois novas formas de internacionalização estão sendo aplicadas. As operações internacionais da marca compreendem a exportação direta para varejistas, a formação de alianças estratégicas com distribuidores não exclusivos e investimentos diretos, com o escritório de distribuição estabelecido em Barcelona, Espanha. Este escritório, por dois anos (2004 e 2005), coordenou a distribuição na própria Espanha e na França, Alemanha, Inglaterra, Itália, Bélgica, Áustria, Suíça e Holanda. Em razão de decisões estratégicas e da necessidade de redução de custos fixos, a unidade européia foi fechada por tempo indeterminado, passando a distribuição a ser gerida por distribuidores não exclusivos, por meio de alianças estratégicas. As estratégias de internacionalização utilizadas pela empresa estão representadas na Figura 3.

Figura 3: Estratégias de Internacionalização de “A”

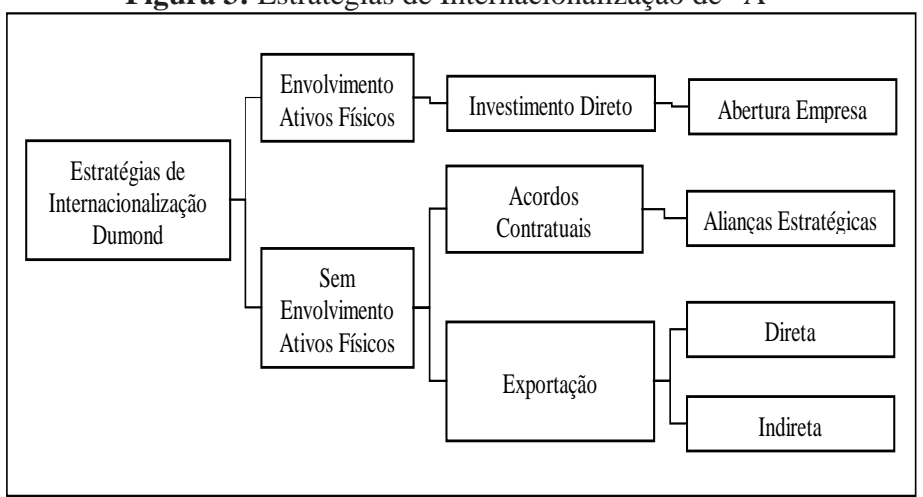

Fonte: Elaboração dos autores.

Outro passo que a empresa desenvolveu foi verticalizar a cadeia de valor para alguns países, com a abertura de lojas monomarca “A” com parceiros locais. Neste caso, a empresa opta pela estratégia de quase integração, minimizando a necessidade de investimentos em ativos fixos e permitindo maior flexibilidade, além de outras vantagens características desta estratégia.

A abertura de canais exclusivos proporcionou uma integração das atividades da cadeia de valor, desde as atividades internas até a distribuição final no varejo. Embora a estratégia a ser utilizada seja a quase integração, a empresa ainda pode usufruir dos benefícios de uma integração total, obtendo dados diretamente do mercado consumidor e criando um relacionamento mais estreito com empresas adjacentes.

Pelo fato de várias estratégias 'conviverem' no ambiente interno da unidade "A" - exportações diretas ainda mantidas, alianças estratégicas, entre outras formas - identifica-se que, embora a palavra 'processo' esteja contida na conceituação de internacionalização, não há obrigatoriedade de etapas seqüenciais rígidas e impositivas.

O processo de aprendizado a partir da lógica buyer driven na empresa facilitou o início, em 1999, das exportações diretas mencionadas. As primeiras exportações diretas por terem sido para um destino próximo (Argentina), sugerem também um aprendizado na organização. Este processo, segundo Johanson e Vahlne (1977), promove condições psíquicas e estruturais para a ampliação da internacionalização para outros destinos.

A primeira investida no mercado alemão ocorreu em 2003, através de aliança estratégica com empresa européia. Este parceiro, localizado na Espanha, operava com uma equipe de vendas própria na Alemanha. Esta parceria durou apenas uma temporada e foi dissolvida sem que as vendas efetuadas fossem efetivamente entregues aos clientes finais. Segundo a responsável pela área de Vendas, este fato gerou problemas de imagem à empresa/marca.

No princípio de 2004, a primeira operação internacional com investimento direto da empresa " $\mathrm{A}$ " foi efetivada, com a abertura da "A" Calzados Europe, localizada em Barcelona, Espanha. Esta operação foi conduzida por um executivo brasileiro oriundo do grupo no Brasil e respondeu pela distribuição aos principais países da Europa, com a formação de equipes de vendas locais nestes países até o final de 2005. As primeiras vendas efetuadas através da empresa “A” Calzados Europe ocorreram no segundo semestre de 2004.

A empresa "A” opera no mercado alemão através de aliança estratégica com uma empresa local de distribuição. Esta empresa, juntamente com o gerente de exportação, seleciona a coleção de produtos dentro das necessidades do mercado e promove a comercialização em todo o país, através de equipe própria de vendas. Houve um salto de vendas da marca, a qual apresentou crescimento de 486,5\% em somente um ano. Entretanto, este percentual é alto em função da pequena base 
inicial. (Tabela 2)

Tabela 2: Desempenho de vendas “A” na Alemanha

\begin{tabular}{|l|c|c|}
\hline Ano & Ano 1 & Ano 2 \\
\hline Pares & 65 & 3.900 \\
\hline $\begin{array}{c}\text { Crescimento } \\
\%\end{array}$ & - & $486,5 \%$ \\
\hline
\end{tabular}

Fonte: Elaboração dos autores.

As operações na Alemanha são realizadas por uma empresa especializada em importações e distribuição. Esta conta com equipe especializada na venda de calçados a todos os canais do varejo alemão. O relacionamento entre a empresa brasileira e a empresa alemã ocorre por acordo de distribuição exclusiva e representação dos interesses da marca na Alemanha. Embora haja acompanhamento dos resultados de parte da empresa "A", não existe ingerência da detentora da marca nas atividades da distribuidora. A estratégia de internacionalização utilizada no mercado alemão tem sido desenvolvida através de alianças estratégicas.

A vendedora alemã entrevistada apontou que a não exclusividade da empresa distribuidora pode ser um problema para o futuro da marca neste mercado. Esta empresa possui outros negócios já maduros e estabelecidos, o que pode deixar os negócios com a marca “A” numa posição secundária.

A estratégia utilizada foi reaplicada para a Escandinávia, o que, segundo a gerência de exportação, confirmaria a viabilidade desta escolha. Para o gerente de exportação, as vantagens de menor risco e menor investimento são um contraponto desta perda de ‘contato’ com o mercado.

Para a vendedora responsável pelas vendas na Alemanha, o ideal seria uma maior proximidade da empresa junto aos varejistas, visando desenvolver maior confiança e a confirmação da proposta de valor e de desenvolvimento da marca. Conforme informações dos entrevistados, a "A” atua no mercado alemão buscando uma estratégia de diferenciação com produtos de maior valor agregado que o tradicional calçado brasileiro. Embora a marca esteja buscando se posicionar como uma estratégia de diferenciação, esta permanece ainda fortemente exposta à pressão por custo. Segundo os entrevistados, o preço dos produtos da marca "A” deve ser posicionado abaixo de marcas italianas e espanholas. Este posicionamento decorre da origem brasileira da marca, que ainda traz consigo a imagem de produto barato ligada à história das exportações brasileiras no setor.

\section{Conclusões}

Este estudo identificou que, na busca de reversão do modelo tradicional buyer driven (corrente no grupo empresarial estudado) para producer driven, a empresa alterou sua estratégia de negócios para diferenciação de produto através de um upgrading funcional. Esta alteração está próxima à lógica producer driven, na qual o produtor exerce papel principal na coordenação de redes de fabricação (GEREFFI, 2001).

Embora a estratégia competitiva da empresa "A" seja de diferenciação de produto, os entrevistados destacaram a necessidade de o preço final estar ajustado às necessidades do mercado e dentro do que se espera de uma marca made in Brazil - ligeiramente inferior às marcas européias (Itália e Espanha). Vale ressaltar que este mercado é caracteristicamente desfavorável para a competição por custo pela pressão das competidoras chinesas.

Quanto à estratégia de internacionalização, enquanto as empresas do modelo tradicional atuam via trading companies ou exportando diretamente, "A" tem desenvolvido alianças estratégicas e investimentos diretos. Outra opção apresentada para o crescimento da marca no mercado alemão é abertura de lojas exclusivas. Para isto, há necessidade de aumentar a penetração da marca no mercado alemão, o que poderia estimular o investimento de empresas locais na abertura de franquias, conforme ocorreu em outros mercados (Brasil e América Latina).

Como implicação gerencial deste estudo, destaca-se que o caso da empresa "A" caracteriza um processo de upgrading industrial completo (produto, processo e funcional). Conforme Pietrobelli e Rabellotti (2004), este tipo de upgrading implica a subida da 'escada' de valor e o distanciamento de atividades nas quais a forma de competição é por custo e as barreiras de entradas são baixas. É comum encontrar no estudo de cadeias globais de valor, estudos de caso sobre upgrading de produto e processo (BAZAN; NAVAS-ALEMÁN, 2004). Estes têm como característica comum o estudo de cadeias de valor buyer driven (GEREFFI, 1999, 2001, 2001a, 2001b; GEREFFI, HUMPHREY; STURGEON, 2005; PIETROBELLI; RABELLOTTI, 2004; SCHMITZ, 2004;SCHMITZ; KNORRINGA, 2000). Alguns 
analisam também o downgrading funcional (RABELLOTTI, 2004).

Ao tratar-se especificamente do processo de internacionalização, observa-se que a experiência anterior de mais de 30 anos operando no modelo buyer driven facilitou o upgrading funcional para a lógica producer driven ou, pelo menos, para uma proposta mais próxima da chamada relações de mercado. O início das exportações diretas para a Argentina no final da década de 90 foi chave no aprendizado e superação da chamada distância psíquica para a ampliação das vendas internacionais da empresa. Este processo de ampliação tem se caracterizado como dinâmico na adaptação a diferentes formas de transação para mercados internacionais. Este dinamismo ficou explícito pelas mudanças ocorridas nas estratégias utilizadas pela empresa estudada. A busca por uma estratégia de maior comprometimento em relação ao mercado internacional é resultado de um aprendizado técnico obtido nas relações comerciais com grandes distribuidores norte-americanos e no desenvolvimento de atividades de branding e marketing.

Vale ressaltar que a natureza deste estudo não permite generalizações para outras empresas calçadistas ou para outras indústrias. Entretanto, os resultados sugerem que a empresa, na perseguição de seu reposicionamento estratégico e conseqüente internacionalização tem buscado: agregar valor ao produto; gerenciar sua cadeia de suprimentos de forma integrada e manter relações mais próximas ao mercado, incluindo alianças estratégicas e outras ações de quase integração com seus fornecedores e clientes.

Estas ações podem servir de indicações possíveis para outras empresas do setor calçadista ou de outros setores que busquem desenvolver um upgrading industrial visando agregar maior valor aos seus produtos nos mercados externos. Sugeremse também novas pesquisas em outros setores exportadores que operam numa lógica buyer driven, setores tradicionalmente de tecnologias mais maduras como móveis, bem como ampliar este estudo para amostras representativas do setor calçadista brasileiro.

\section{REFERÊNCIAS}

ANDERSEN, Otto. Internationalization and Market Entry Mode: A Review of Theories and Conceptual Frameworks. Management International Review, v.37, Special Issue, p. 27-42, 1997. < http://dx.doi. org/10.2307/40228431>
BAZAN, L.; NAVAS-ALEMÁN, L. The underground revolution in the Sinos Valley: a comparison of upgrading in global and national value chains. In: SCHMITZ, H., (ed). Local Enterprises in the Global Economy - Issues of Governance and Upgrading. Cornwall: MPG Books Ltd, 2004.

BUCKLEY, P. O Futuro da Empresa Multinacional. In: FUNDAÇÃO DOM CABRAL. Internacionalização de Empresas Brasileiras. Rio de Janeiro: QualityMark, 1996.

CATEORA, P. R. International Marketing, Boston: McGraw-Hill, 1999.

CAVUSGIL, S. T. On the Internationalization Process of Firms. European Research, v.8, p.273-281. 1980.

COSTA, A. B. A trajetória competitiva da indústria de calçados do Vale dos Sinos. In: A indústria calçadista do Rio Grande do Sul. São Leopoldo: Unisinos, 2004.

DE TONI, A.; FILIPPINI, R.; FORZA, C. Manufacturing strategy in global markets: an operations managementmodel.International Journal of Operations \& Production Management, v. 12, n. 4, p. 7-18. 1992. <http://dx.doi.org/10.1108/01443579210011561>

DICKEN, P. Global Shift: Reshaping the Global Economic Map in the 21st Century. 4. ed. London: Sage, 2003.

DUNNING, J. H. The Eclectic Paradigm of International Production: A Restatement and Some Possible Extensions. Journal of International Business Studies, v. 19, p. 1-31. 1988. < http://dx.doi.org/10.1057/ palgrave.jibs.8490372>

ELLRAM, L. M. Patterns in International Alliances. Journal of Business Logistics, v.12, n.1, p.1-25. 1992.

FATEHI, K. International management: a crosscultural and functional perspective. Upper Saddle River: Prentice Hall, 1996.

FLICK, U. Pesquisa Qualitativa. Porto Alegre: Bookman, 2004.

GEREFFI, E. V. Upgrading Brazilian Footwear: The Challenge of Brand Development and Marketing Management in the Sinos Valley. Washington: Georgetown University, 2004.

GEREFFI, G. International trade and industrial upgrading in the apparel commodity chain. Journal of International Economics, v. 48, p. 37-70. < http:// dx.doi.org/10.1016/S0022-1996(98)00075-0>

GEREFFI, G. Shifting Governance Structures in Global Commodity Chains, With Special Reference to the Internet. American Behavioral Scientist, v. 44, n. 10, p. 1616-1637. 2001. <http://dx.doi. org/10.1177/00027640121958087>

GEREFFI, G. The Global Economy: Organization, Governance, and Development. The Handbook of Economic Sociology, 2. ed. Princeton: Princeton University Press and Russel Sage Foundation, 2005.

GEREFFI, G. The organization of buyer-driven global commodity chains: how US retailers shape 
overseas production networks. In: Beyond the Producerdriven/Buyer-driven Dichotomy. IDS Bulletin, Brighton, v.32, n.3. 2001.

GEREFFI, G.; KORZENIEWICZ, M. (eds) Global Commodity Chains - Contributions in economics and economic history. Connecticut and London: Praeger, 1994.

GEREFFI, G.; HUMPHREY, J.; STURGEON, $\mathrm{T}$. The governance of global value chains. Review of International Political Economy, v. 12, n. 1, p. 78-104, 2005. < http://dx.doi.org/10.1080/09692290500049805>

GOULART, L.; BRASIL, H. V.; ARRUDA, C. A. A internacionalização de empresas brasileiras: motivações e alternativas. In: Equipe de Internacionalização da Fundação Dom Cabral (Org.). Internacionalização de Empresas Brasileiras. Rio de Janeiro: Qualitymark, 1996.

GOVINDARAJAN, V.; GUPTA, A. K. The Quest for Global Dominance: Transforming Global Presence into Global Competitive Advantage. San Francisco: Jossey-Bass, 2001.

HARRIGAN, K. R. Strategic Flexibility: a management guide for changing times. New York, Lexington Books, 1985.

JOHANSON, J.; VAHLNE, J. E. The Internationalization Process of the Firm - A Model of Knowledge Development and Increasing Foreign Market Commitments. Journal of International Business Studies, v. 8, p. 23-32, 1977. < http://dx.doi.org/10.1057/ palgrave.jibs.8490676>

KEEGAN, W. J.; GREEN, M. C. Princípios de marketing global. São Paulo: Saraiva, 1999.

KOGUT, B. Designing Global Strategies: Comparative and Competitive Value-Added Chains. Sloan Management Review, v.26, n. 4, p.15-28, 1985. < http://rrojasdatabank.info/kogut1985.pdf $>$

KOTLER, P. Administração de Marketing: análise, planejamento, implementação e controle. São Paulo: Atlas, 1998.

LU, J. W.; BEAMISH, P. W. The Internationalization and Performance of SMEs. Strategic Management Journal, v. 22, n. 6, p. 565-586, 2001. <http://dx.doi. org/10.1002/smj.184>

Melin, L. Internationalization as a strategy process, Strategic Management Journal, v.13, n.2, p. 99-118, 1992. <http://dx.doi.org/10.1002/smj.4250130908>

MINERVINI, N. O Exportador. São Paulo: Makron Books, 2001.

PAN, Y.; TSE, D. K. The Hierarchical Model of Market Entry Modes. Journal of International Business Studies, v.31, p.535-554, 2000. <http://dx.doi. org/10.1057/palgrave.jibs.8490921>

PHATAK, A. V. International management: concepts and cases. Cincinnati: South-Western College Publishing, 1996.

PIETROBELLI, C.; RABELLOTTI, R. Upgrading in Clusters and Value Chains in Latin America: the role of policies. Inter-American Development Bank,
2004.

PIPKIN, A. Marketing Internacional. São Paulo: Aduaneiras, 2000.

PORTER, M. E. Competitive strategy. New York: The Free Press, 1980.

PORTER, M. E. The Competitive Advantage of Nations. Harvard Business Review, p.73-93, Mar./Apr. 1990.

RABELLOTTI, R. How globalization affects Italian industrial districts: The case of Brenta. RSA International Conference, Pisa, 2003. <http:// www.inti.gov.ar/cadenasdevalor/documentacion/ distritosindustrialesenitalia.pdf $>$

ROCHA, A. da. Prefácio. In: ROCHA, A. da (Org.). A Internacionalização das Empresas Brasileiras: estudos de gestão internacional. Rio de Janeiro: Mauad, 2002.

ROESCH, S. M. A. Projetos de Estágio e de Pesquisa em Administração. 2. ed. São Paulo: Atlas, 1999.

ROOT, F. Entry Strategies for International Markets. Lexington, MA: Lexington Books, 1987.

SCHMITZ, H. Local Enterprises in the Global Economy: Issues of Governance and Upgrading. Cornwall: MPG Books Ltd, 2004.

SCHMITZ, H.; KNORRINGA, P. Learning from Global Buyers. IDS Working Paper, n. 100. 2000.

STABLEIN, R. Dados em estudos organizacionais. In: CLEGG, S.; HARDY, C.; NORD, W. Handbook de estudos organizacionais. São Paulo: Atlas, 2001.

STAKE, R. E. Handbook of qualitative research. Thousand Oaks: Sage Publications, 1994.

TURNBULL, P. W. A challenge to the stages theory of the internationalization process. In: ROSSON P.J.; REID, S.D. (eds). Managing Export Entry and Expansion, New York: Praeger, 1987.

WALTERS, B. A.; PETERS, S.; DESS, G. G. Strategic Alliances and Joint Ventures: Making them Work. Business Horizons, 1994.

WILLIAMSON, O. E. Economic organization: Firms, markets, and policy control. New York: NYU Press, 1986.

YIN, R. K. Estudo de caso: planejamento e métodos. 2. ed. Porto Alegre: Bookman, 2001. 